\title{
Auscultatory and phonocardiographic findings in Ebstein's anomaly Correlation of first heart sound with ultrasonic records of tricuspid valve movement ${ }^{2}$
}

\author{
Thomas L. Crews, Ronald B. Pridie, ${ }^{2}$ Ramsey Benham, and Aubrey Leatham \\ From the Cardiac Department of St. George's Hospital, London, \\ and the Department of Medicine (Clinical Cardiology), Hammersmith Hospital, London
}

The heart sounds and murmurs are described in ro patients with Ebstein's anomaly, in 6 of whom the diagnosis had been confirmed by catheterization and angiocardiography or by necropsy.

While wide splitting of the second sound, diastolic sounds, pansystolic murmurs, and diastolic murmurs were found in most, the only constant abnormality was abnormally wide splitting of the first sound with accentuation of the delayed component. This abnormal sound was thought to be caused by delayed closure of the abnormally large anterior leaflet of the tricuspid valve, especially as its delay was almost exactly related to the degree of right bundle-branch block.

Ultrasonic recordings from the tricuspid valve and mitral valve with simultaneous phonocardiograms were successfully obtained in 3 cases. While mitral closure occurred at the normal time, tricuspid closure was greatly delayed and coincided exactly with the abnormal sound.

It is concluded that tricuspid closure tends to be abnormally loud and late in Ebstein's anomaly serving as a useful sign in diagnosis. Furthermore, the intensity of the sound despite a hypodynamic right ventricle is of interest in relation to the mechanism of heart sounds.

Abnormalities of heart sounds are almost invariable in Ebstein's anomaly but published reports are confusing with a wide variety of findings. We have long suspected that one of the most useful signs is a remarkable delay and increased intensity of the tricuspid component of the first heart sound (Fig. I), and have used the ultrasonic technique to investigate this.

\section{Methods and subjects}

The auscultatory and phonocardiographic findings have been reviewed in Io patients with Ebstein's anomaly seen at St. George's Hospital. The clinical diagnosis was confirmed in 3 patients by catheterization and angiocardiography and in another 3 by necropsy. The remaining 4 patients had sufficient evidence from physical examination, electrocardiogram, and $x$-ray findings to justify a clinical diagnosis of Ebstein's anomaly.

Heart sounds were recorded in all by means of

Received 3I August 197 I.

${ }^{1}$ Presented to the American Heart Association, October 1970, and the British Cardiac Society, Spring 1971 .

2 Supported by British Heart Foundation Award. a 4-channel photographic recorder made by the Cambridge Instrument Company of England. High frequency phonocardiograms from one or two sites together with carotid pulse, respiration, and electrocardiogram were recorded simultaneously. Ultrasonic recordings of tricuspid valve movement with simultaneous phonocardiograms were attempted in 6 patients and were obtained in 3. The ultrasound apparatus was an Eskoline 20 ultrasonic machine ${ }^{1}$ leading into a Cambridge 4-channel recorder and has been described previously (Pridie and Turnbull, 1968; Pridie and Oakley, I970). Short electrical impulses of I $\mu \mathrm{sec}$ duration are applied to a piezoelectric transducer composed of barium titanate crystals. This gives off ultrasound waves which, with the transducer on the praecordium and suitably angled, can be reflected from the anterior cusp of either the mitral or tricuspid valves (Edler and Hertz, 1954) back to the transducer where secondary currents are induced. The interval between the initial and secondary impulses can be displayed on an oscilloscope and is proportional to the distance of the reflecting surfaces from the transducer. Vertically continuous traces of the valve's position are obtained by repeating the impulses 1000 times a

${ }^{1}$ Smith Kline Instruments Limited, Welwyn Garden City, Herts. 
second and records made by photographing the oscilloscope, or by transferring the signal by use of an electronic gate to a multichannel recorder.

In all the illustrations in this paper the initial signal is at the top. Hence, opening movements of the anterior cusp of both the mitral and tricuspid valves are shown as upward deflections and closing movements as downward deflections.

\section{Results}

Auscultatory and phonocardiographic findings (Table) First heart sound The first heart sound was obviously split to auscultation in all ro patients and this was confirmed by phonocardiography in every case (Fig. 2 and 3). The first component was attributed to mitral closure $\left(M_{1}\right)$ and occurred at the normal time $(0.05$ to $0.08 \mathrm{sec}$ after the onset of QRS) and tended to be soft. A later sound, 0.05 to $0.12 \mathrm{sec}$ after $M_{1}$, was heard and recorded in every one of the ro patients. This was attributed to tricuspid closure $\left(T_{1}\right)$, delayed by complete right bundle-branch block in 9 of the cases, and the width of splitting correlated approximately with the width of QRS (Table): the patient with the most widely split $S_{1}(0.12 \mathrm{sec})$ had the widest QRS $(0.18 \mathrm{sec})$ : catheterization in 2 of them confirmed delay in onset of the right ventricular pressure pulse. In Case I with a normal
QRS complex, the onset of the right ventricular pressure pulse was nevertheless delayed, shown by a prolonged Q-RV time at cardiac catheterization. The intensity of the sound thought to be due to tricuspid closure $\left(T_{1}\right)$ was increased in relation to $M_{1}$ and was usually an obvious physical sign (Fig. 2 and 3 ).

Second heart sound The second heart sound was single ( $A_{2}$ alone) in 3 patients (Fig. 2, 3 , and 4) and, as suggested by Genton and Blount (1967), it was thought that $P_{2}$ could not be demonstrated because of the low pressure in the pulmonary artery. In the other 7 patients, $P_{2}$ was soft, and the splitting was abnormally wide with $\mathrm{A}_{2}-\mathrm{P}_{2}$ intervals of 0.03 sec or more during expiration, fixed or increasing slightly on inspiration: the width of splitting corresponded to the right bundlebranch block.

Diastolic sounds In 9 patients, a high frequency diastolic sound was heard and recorded from the lower left sternal edge and varied from 0.05 to $0.15 \mathrm{sec}$ after $P_{2}$. The time interval from $P_{2}$ to the diastolic sound could not be measured in the 3 cases where $P_{2}$ was too soft to be recorded. In these cases $P_{2}$ was assumed to be delayed in proportion to the degree of right bundle-branch block $\left(\mathrm{A}_{2}-\mathrm{P}_{2}\right.$ interval $=\mathrm{QRS}$ width $>0.08 \mathrm{sec})$. An atrial

TABLE Phonocardiographic findings

\begin{tabular}{|c|c|c|c|c|c|c|c|c|c|c|c|c|c|}
\hline \multirow{2}{*}{$\begin{array}{l}\text { Case } \\
\text { No. }\end{array}$} & \multirow{2}{*}{$\begin{array}{l}\text { Age } \\
(y r)\end{array}$} & \multirow{2}{*}{$\begin{array}{l}\text { QRS } \\
\text { width }\end{array}$} & \multirow{2}{*}{$\begin{array}{l}\text { Width } \\
\text { split I }\end{array}$} & \multirow[t]{2}{*}{$Q-M_{1}$} & \multirow[t]{2}{*}{$Q-T_{1}$} & \multirow[t]{2}{*}{$Q-R V$} & \multirow[t]{2}{*}{$A_{2}-P_{2}$} & \multirow[t]{2}{*}{$P_{2}-O S$} & \multirow{2}{*}{$\begin{array}{l}P \text {-atrial } \\
\text { sound }\end{array}$} & \multirow[t]{2}{*}{$R R$} & \multicolumn{2}{|l|}{$V F M$} & \multirow{2}{*}{$\begin{array}{l}\text { Syst. } \\
\text { murmur } \\
\text { after } T_{1}\end{array}$} \\
\hline & & & & & & & & & & & Post OS & Post $P$ & \\
\hline \multirow[t]{2}{*}{ I } & 9 & 0.08 & 0.05 & 0.05 & 0.10 & 0.11 & 0.04 & 0.06 & 0.12 & 0.68 & $x$ & 0.12 & Pan \\
\hline & & & & & & & 0.05 & & & & & & \\
\hline \multirow[t]{2}{*}{2} & 3 & 0.10 & 0.05 & 0.07 & 0.12 & - & 0.08 & 0.08 & - & 0.48 & + & $-s$ & Pan \\
\hline & & & & & & & 0.04 & & & & & & \\
\hline 3 & 35 & 0.12 & 0.05 & 0.06 & 0.1 I & O.II I & $\begin{array}{l}0.03 \\
0.05\end{array}$ & 0.15 & $-\mathbf{z}$ & $\begin{array}{l}I \cdot I 8 \\
\quad \text { varies }\end{array}$ & + & - & - \\
\hline 4 & I & 0.12 & 0.06 & 0.06 & 0.12 & - & 0.05 & 0.05 & - & 0.48 & + & $-\mathrm{s}$ & Pan \\
\hline 5 & 44 & 0.12 & 0.06 & 0.06 & $0.12+$ & 0.1 I & Single & $0 . I^{\star}{ }^{\star}$ & 0.14 & 0.8 & - & 0.14 & - \\
\hline 6 & 18 & 0.12 & 0.07 & 0.05 & 0.12 & - & Single & $0.07^{\star}$ & 0.13 & 0.6 & + & - & Early \\
\hline 7 & 64 & 0.12 & 0.07 & 0.08 & 0.15 & - & $\begin{array}{l}0.06 \\
0.08\end{array}$ & 0.13 & - & 0.66 & - & - & - \\
\hline 8 & 35 & 0.12 & 0.08 & 0.08 & 0.16 & - & $\begin{array}{l}0.04 \\
0.06\end{array}$ & - & - & - & - & - & - \\
\hline 9 & 27 & 0.15 & 0.10 & 0.08 & 0.18 & - & Single & $0.14^{\star}$ & 0.16 & 0.86 & - & - & Pan \\
\hline 10 & 48 & 0.18 & 0.12 & 0.12 & 0.24 & - & 0.10 & 0.12 & $\begin{array}{l}0.09 \\
0.28\end{array}$ & $I \cdot I 6$ & + & 0.09 & Pan \\
\hline
\end{tabular}

$\mathbf{A}_{2}-\mathbf{P}_{2}=$ Interval between aortic and pulmonary components of the second sound.

$\mathbf{P}_{2}-\mathrm{OS}=$ Interval between $A_{2}$ and presumed opening snap.

VFM $=$ Ventricular filling murmur.

$\mathrm{z}=$ Multiple sounds from flutter - one $0.05 \mathrm{sec}$ after onset $\mathbf{P}$.

$\mathrm{s}=$ Summation.

$\star$ Timing of $P_{2}$ calculated from QRS delay.

$Q-M_{1}=$ Onset of QRS to onset of first component of 1 st sound.

Q- $T_{1}=$ Onset of QRS to onset of second component of ist sound.

$\mathrm{Q}-\mathbf{R V}=$ Onset of QRS to onset of right ventricular pressure pulse. 
FIG. I Phonocardiogram (medium frequency $M F)$ recording from apex $(M A)$ taken by one of us for Medd et al. (I954) showing wide splitting of first sound with late loud component after carotid $(C A R)$ rise and attributed to delay in tricuspid closure $\left(I^{1}\right)$. There is a pansystolic murmur ( $S M)$ from $I^{1}$ probably extending to $P_{2}$. Wide splitting of second sound with soft late pulmonary component $\left(P_{2}\right)$ shown in high frequency recording from pulmonary area (HF PA). Diastolic sounds $(X)$ and variable diastolic murmur (DM).

FIG. 2 Phonocardiogram from lower left sternal edge (LSE) in Case 5 showing wide splitting of first heart sound ( $I$ and $\left.I^{\prime}\right)$, single second sound (2), opening snap $(X)$, and atrial systolic murmur (ASM). $I^{\prime}$ is preceded by carotid rise (when corrected 0.03 sec for delay) and both $I^{\prime}$ and $X$ are slightly larger during inspiration (INSP).
FIG. 3 Phonocardiogram in Case 9 showing loud late component of first heart sound $\left(I^{\prime}\right)$, systolic murmur ( $S M)$, single second sound, opening snap $(X)$, and atrial sound $(A)$.
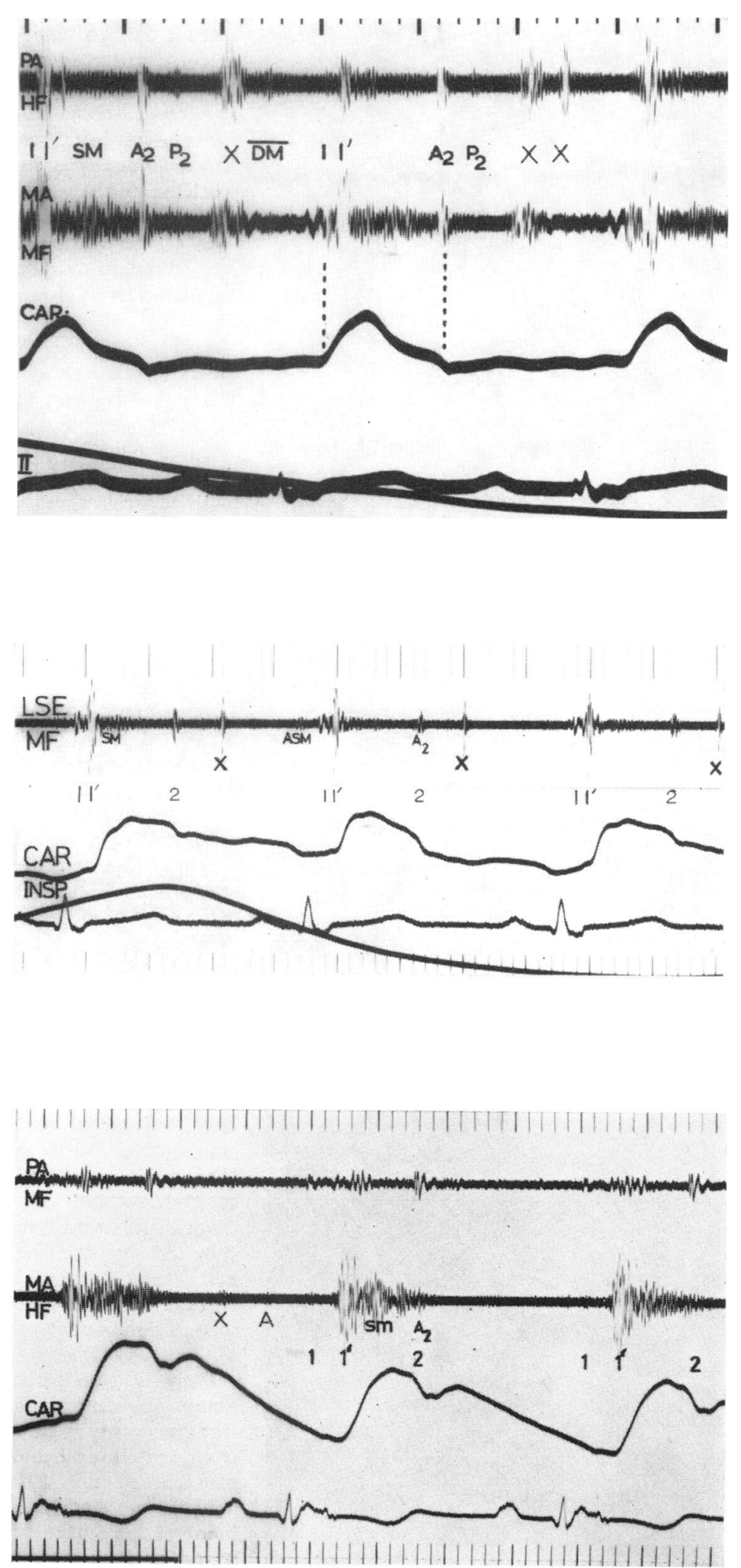


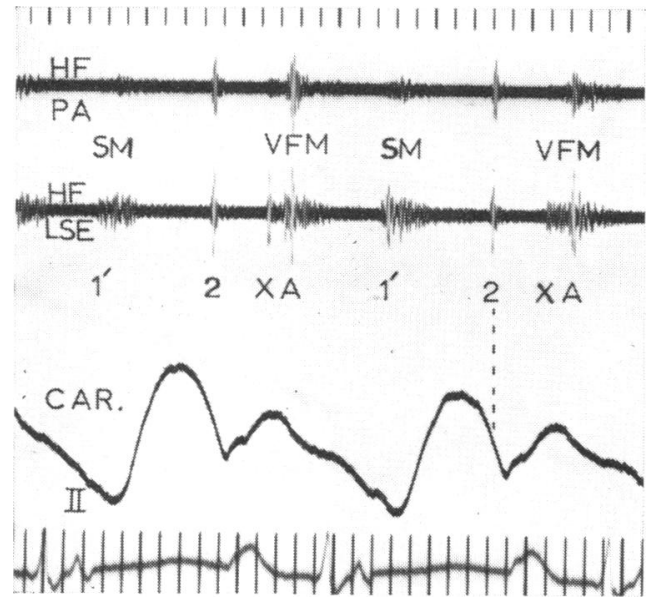

FIG. 4 Phonocardiogram in Case 6 showing late $I^{\prime}$, short systolic murmur, single second sound, and two loud diastolic sounds $(X, A)$, the second probably being related to atrial contraction. Each of these sounds appears to be followed by a short ventricular filling murmur (VFM).

FIG. 5 Untouched ultrasound recording of one of the cases showing movement of both tricuspid and mitral valves. Upward movement is opening and downward movement is closure. From above - electrocardiogram, $R V$ free wall echo, tricuspid echogram, septal echo, mitral echogram, and $L V$ free wall echo. Mitral closure (downstroke movement) precedes tricuspid closure (downstroke).

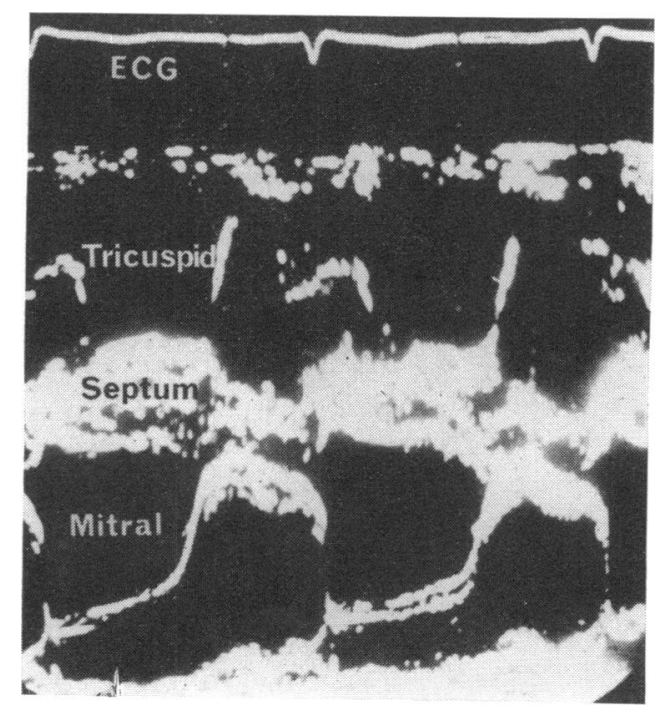

sound 0.09 to $0.16 \mathrm{sec}$ after onset of $P$ was recorded in 5 patients (Fig. 3 and 4 ).

Systolic murmur A soft or moderately loud systolic murmur maximal at the lower left sternal edge was heard and recorded in 7 patients and was usually pansystolic in relation to right ventricular systole $\left(\mathrm{T}_{1}-\mathrm{P}_{2^{-}}\right.$ Fig. 3), but the duration of the softer murmurs was difficult to define and they sometimes appeared short (Fig. 2).

Diastolic murmur Ventricular filling murmurs were recorded in 7 cases (Table). In 6 cases the murmur started with the diastolic sound (Fig. 4) and in 2 may have been augmented later by atrial contraction (summation): in 2 a second diastolic murmur started with an atrial sound. In the 7th case there was an atrial murmur alone (Fig. 2).

Ultrasonic study of tricuspid valve movement Since the anterior cusp of the tricuspid valve in Ebstein's anomaly is usually normally placed and quite large (Hudson, 1965; Hardy and Roe, 1969), it was felt that its movement might be recorded by means of an ultrasound echogram. Satisfactory records of tricuspid movement with simultaneous phonocardiograms were obtained in 3 patients. In 2 further patients there were echoes from the tricuspid valve on the oscilloscope, but it was not possible to transfer the signal to the multichannel recorder because of interference by echoes from the anterior heart muscle.

While normal placement of mitral and tricuspid valves requires quite different angulation of the transducer for each valve, it was possible in one case of Ebstein's anomaly to obtain echoes from both mitral and tricuspid valves on the same recording, and it was shown that tricuspid closure was significantly later than mitral closure (Fig. 5). In 3 cases, consecutive mitral and tricuspid ultrasonic echograms, each with simultaneous phonocardiogram and electrocardiogram, showed that closure of the mitral anterior leaflet corresponded with the first component of the split first heart sound $\left(M_{1}\right)$, and closure of the anterior leaflet of the tricuspid valve with the second component of $S_{1}\left(T_{1}\right.$, Fig. 6, 7, and 8).

Only in two patients were phonocardiograms showing a diastolic sound obtained simultaneously with the ultrasonic records from both mitral and tricuspid valves. The problem in the other cases was that the microphone had to be displaced from the point of maximum intensity of the diastolic sound because that was the only point from 


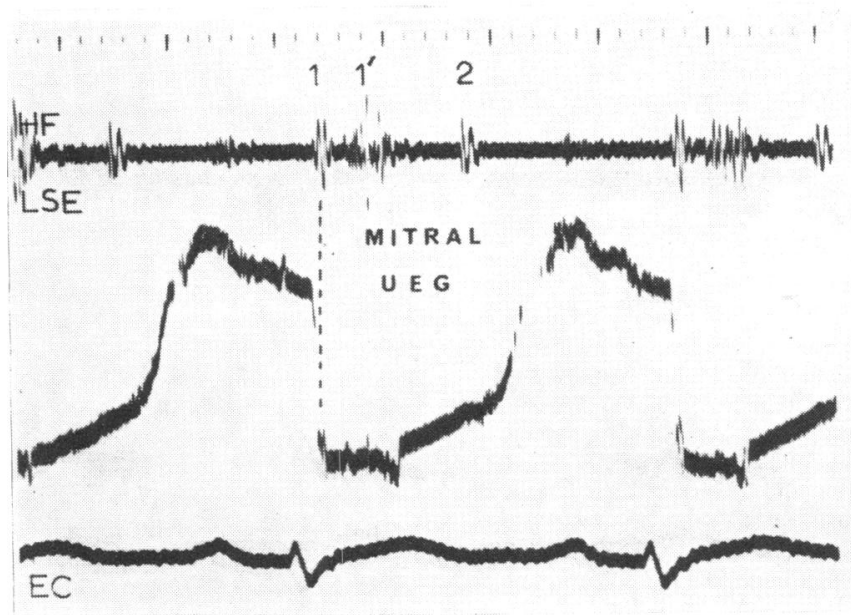

(a)

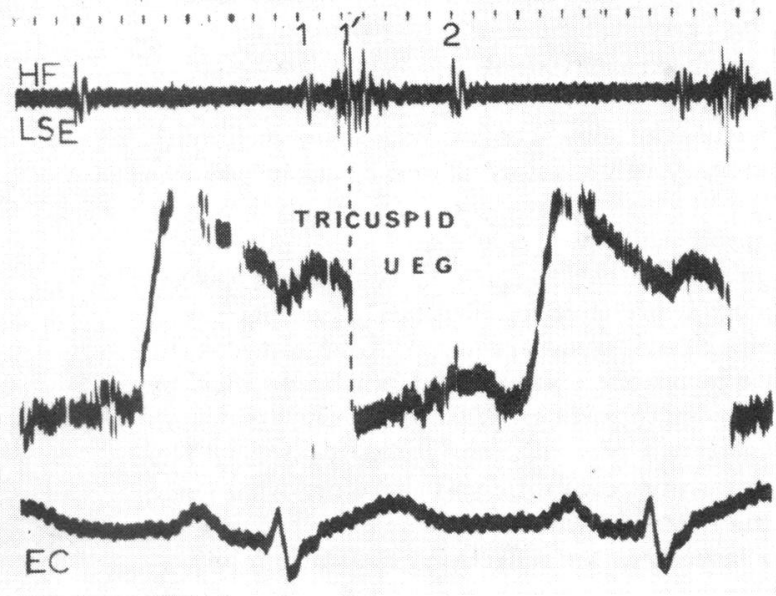

(b)

FIG. 6 Phonocardiogram with mitral ultrasonic echogram (a) and with tricuspid ultrasonic echogram $(b)$ in Case 9. The first component of the first sound $(I)$ coincides with mitral closure and the second component $\left(I^{\prime}\right)$ with tricuspid closure.

which tricuspid valve echoes could be recorded. In the two patients the diastolic sound occurred immediately after the tricuspid valve had reached the fully open position (Fig. 9). One further patient had a similar heart rate both when a standard phonocardiogram was made and at the time of the ultrasonic echogram, and measurement from the $R$ wave of the electrocardiogram to the diastolic sound corresponded exactly with the measurements from the $R$ wave to the peak of the tricuspid opening movement on the echogram.

\section{Discussion}

An obvious sound in early systole creating the impression of wide splitting of the first sound, and useful in clinical diagnosis, was present in every one of the ro patients. We have attributed this sound, as have others (Schieb- ler et al., 1959), to late tricuspid valve closure caused by delayed onset of the right ventricular pressure pulse from complete right bundlebranch block (Leatham and Gray, 1956). The abnormally great intensity of this sound of tricuspid closure was attributed to the increased size of the anterior leaflet of the tricuspid valve in Ebstein's anomaly, thus increasing its 'sail area' when halting the 'regurgitating' blood column. Audibility of tricuspid closure has been denied by Luisada and others (1967), but is supported by the findings associated with asynchronous ventricular contraction from isolated right bundle-branch block, ectopic beats, and pac-
FIG. 7 Mitral and tricuspid echograms with simultaneous electrocardiogram and phonocardiogram in Case I showing that mitral closure coincides with the first component of the first sound $\left(M_{1}\right)$ and tricuspid closure with the second $\left(T_{1}\right)$. The tricuspid echogram could not be obtained on the multichannel recorder throughout the cycle; valve movement is recorded in systole, i.e. down, but in diastole, because of the anterior heart echoes, it was not possible to obtain undistorted echoes when open. Hence, these echoes have been cut off producing a square appearance but enabling the opening and closure to be timed accurately.

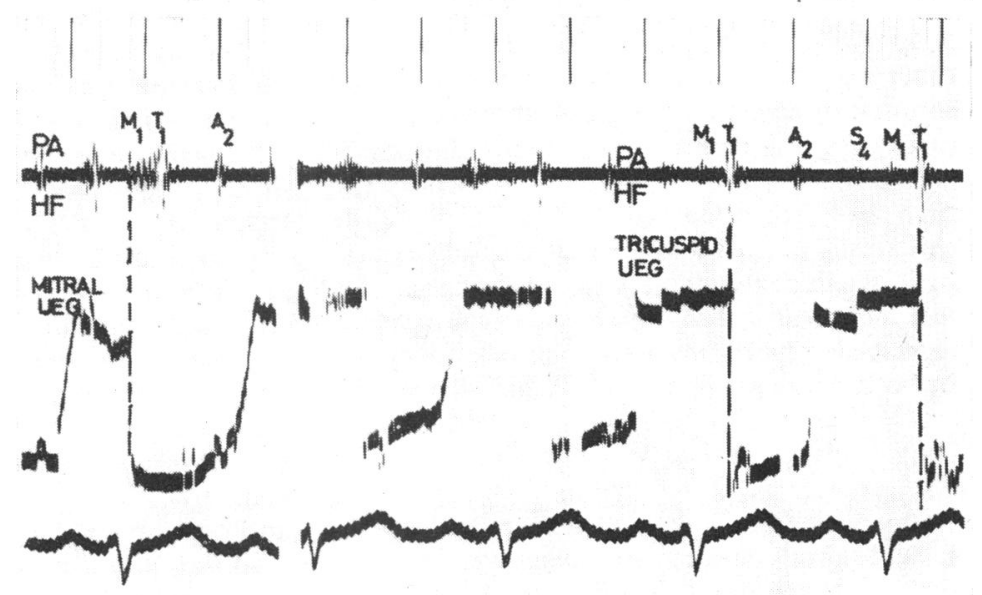


ing (Haber and Leatham, 1965). Alternatively, the early systolic sound of Ebstein's anomaly has been attributed to pulmonary ejection (Genton and Blount, 1967; Schiebler et al., 1959), but this seems unlikely since the pulmonary valve is normal and ejection fractions tend to be small with an abnormally low pulmonary artery pressure and small pulmonary artery, so that the two factors usually associated with ejection sounds (Leatham and Vogelpoel, 1954) are absent. The cause of the early systolic sound could not be decided by cine-angiocardiography since the tricuspid valve was not sufficiently clearly shown. The ultrasonic technique was therefore tried since the tricuspid valve might be expected to have a large area for reflection of ultrasonic vibrations. In the cases where satisfactory recordings could be made, exact synchrony was demonstrated between systolic halting of the Ebstein valve and the early systolic sound. It is therefore reasonable to conclude that the early systolic sound is caused by sudden halting of the tricuspid valve at the limit of its systolic movement.

Abnormally wide splitting of the second sound would have been expected in the 9 cases with complete right bundle-branch block. Indeed, this was found whenever $\mathbf{P}_{2}$ could be recorded. The absence of $P_{2}$ in 3 cases was attributed to the low pulmonary diastolic pressure as suggested by Genton and Blount (1967); in these cases the relatively loud high frequency sound attributed to opening of the tricuspid valve had sometimes been mistaken for $P_{2}$ until it was appreciated that $P_{2}$ was nearly always soft and difficult to hear.

Diastolic sounds are frequently obvious in Ebstein's anomaly. They have been described as tricuspid opening snaps (Genton and Blount, 1967), rapid ventricular filling third sounds (Medd, Matthews, and Thursfield, 1954), and atrial sounds (Genton and Blount, 1967; Ongley, 1957). In 9 of the ro patients there was an obvious high frequency diastolic sound 0.05 to $0.14 \mathrm{sec}$ after $\mathrm{P}_{2}$ and likely to be a tricuspid opening snap and the exact counterpart of the tricuspid component of the first sound or tricuspid closing snap. While this sound is the most obvious diastolic sound in Ebstein's anomaly, we were unable, for technical reasons, to time it with simultaneous ultrasonic recordings, except in two cases and in both of them the sound occurred immediately after the tricuspid valve had opened completely, and was exactly comparable to the relation of the opening snap of mitral stenosis to movement of the mitral valve. Later sounds were also present in 5 cases $0.09-0.14$ sec after the onset of $\mathrm{P}$ and may

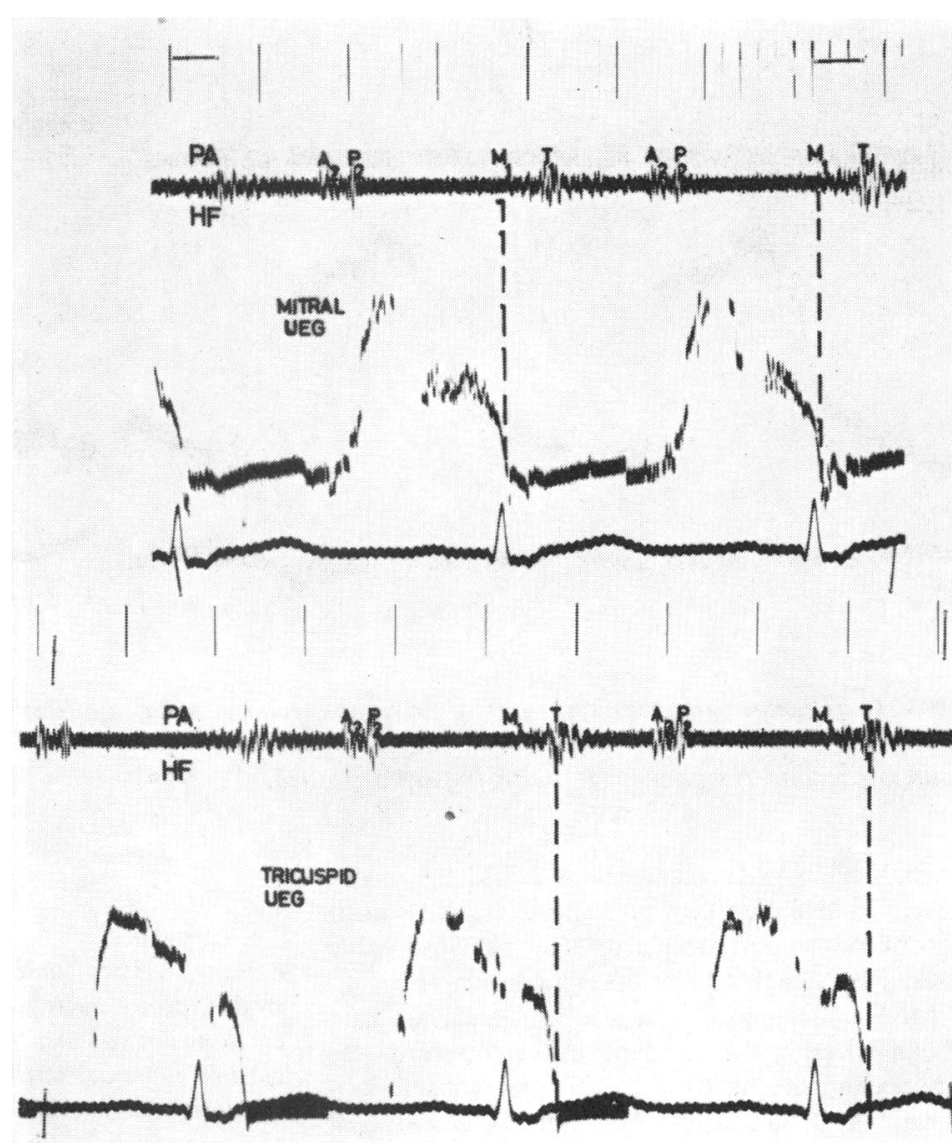

FIG. 8 Tricuspid and mitral ultrasonic echograms in another case, with simultaneous electrocardiogram and phonocardiogram, again demonstrates that $M_{1}$ corresponds to mitral closure and $T_{1}$ corresponds to tricuspid closure.

have been due to reopening of the tricuspid valve after atrial contraction.

Murmurs in Ebstein's anomaly were less obvious physical signs. There was a soft or moderately loud systolic murmur at the lower left sternal edge in 7 cases, and though the duration of a soft murmur was difficult to define, the louder murmurs were pansystolic and were attributed, as in the past (Genton and Blount, 1967; Schiebler et al., 1959), to tricuspid regurgitation despite the frequent absence of respiratory variation in intensity and of a systolic wave in the venous pulse. This may be explained by minimal regurgitation through fenestrations in the otherwise competent anterior tricuspid valve leaflet, and by feeble right ventricular contraction.

Diastolic murmurs due to right ventricular filling were recorded in 7 cases. They started 


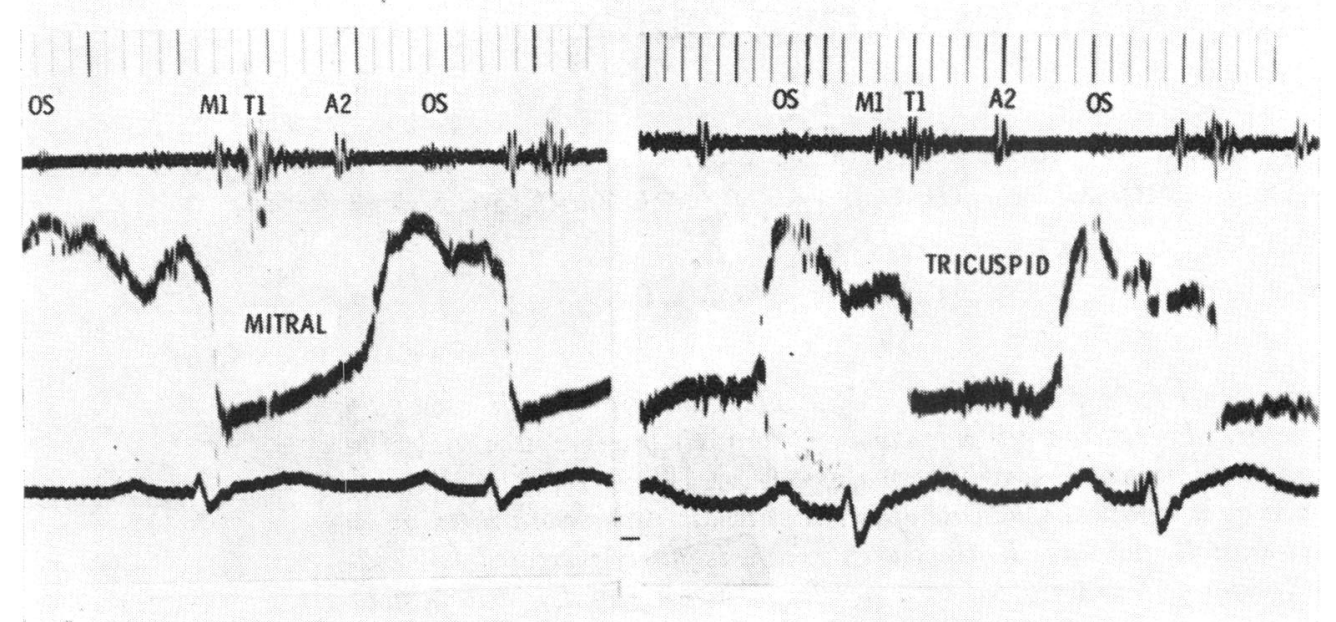

FIG. 9 Synchrony between mitral closure and $M_{1}$, and tricuspid closure and $T_{1}$. The opening snap (OS) occurs at the end of the tricuspid opening movement and is unrelated to mitral opening.

with the sound attributed to opening of the tricuspid valve. In 3 cases a murmur started with an atrial sound suggesting a similar mechanism for this sound as for the earlier sound - reopening of the tricuspid valve.

In conclusion, prominent systolic and diastolic sounds attributed to halting of the large anterior cusp of the tricuspid valve were a useful sign of Ebstein's anomaly. When added to other signs such as an impalpable right ventricle, soft late pulmonary component of the second sound, right bundle-branch block, and radiological evidence of a large right atrium with normal or reduced size of pulmonary artery and pulmonary flow, a clinical diagnosis should be possible in most cases. In the late stages of the disease where there may be gross tricuspid regurgitation and right heart failure, as in a recent 78-yearold who came to necropsy without a clinical diagnosis, the findings may be less clear cut and indeed it is well known that there are many variants of Ebstein's anomaly. In the Io cases studied, the physical sign which proved to be most constantly useful was the greatly delayed and accentuated component of the first heart sound which was shown by ultrasonic studies to coincide exactly with closure of the tricuspid valve.

\section{References}

Edler, I., and Hertz, C. H. (1954). The use of ultrasonic reflectoscope for the continuous recording of the movement of heart walls. Kunglia Fysiografiska Sällskapets I Lund Forhandlingar, 24, 40.
Genton, E., and Blount, S. G. (1967). The spectrum of Ebstein's anomaly. American Heart fournal, 73, 395.

Haber, E., and Leatham, A. (1965). Splitting of heart sounds from ventricular asynchrony in bundle branch block, ventricular ectopic beats, and artificial pacing. British Heart fournal, 27, 691.

Hardy, K. L., and Roe, B. B. (1969). Ebstein's anomaly. Further experience with definitive repair. fournal of Thoracic and Cardiovascular Surgery, 58, 553.

Hudson, R. E. B. (1965). Congenital anomalies of the heart valves. In Cardiovascular Pathology, Vol. 2, p. 1939. Edward Arnold, London.

Leatham, A., and Gray, I. (1956). Auscultatory and phonocardiographic signs of atrial septal defect. British Heart fournal, 8, 193.

Leatham, A., and Vogelpoel, L. (1954). The early systolic sound in dilatation of the pulmonary artery. British Heart fournal, 16, 21.

Luisada, A. A., Kurz, H., Slodki, S. J., MacCanon, D. M., and Krol, B. (1967). Normal first heart sounds with non-functional tricuspid valve or right ventricle. Circulation, 35, 119.

Medd, W. E., Matthews, M. B., and Thursfield, W. R. R. (1954). Ebstein's disease. Thorax, 9, 14.

Ongley, P. A. (1957). Heart sounds in total anomalous pulmonary venous return and in Ebstein's anomaly. Circulation, 16, 431.

Pridie, R. B., and Oakley, C. M. (1970). Mechanism of mitral regurgitation in hypertrophic obstructive cardiomyopathy. British Heart fournal, 32, 203.

Pridie, R. B., and Turnbull, T. A. (1968). Diagnosis of pericardial effusion by ultrasound. British Medical fournal, 3, 356.

Schiebler, G. L., Adams, P., Anderson, R. C., Amplatz, K., and Lester, R. G. (I959). Clinical study of twenty-three cases of Ebstein's anomaly of the tricuspid valve. Circulation, 19, 165.

Requests for reprints to Dr. Aubrey Leatham, St. George's Hospital, London S.W.I. 